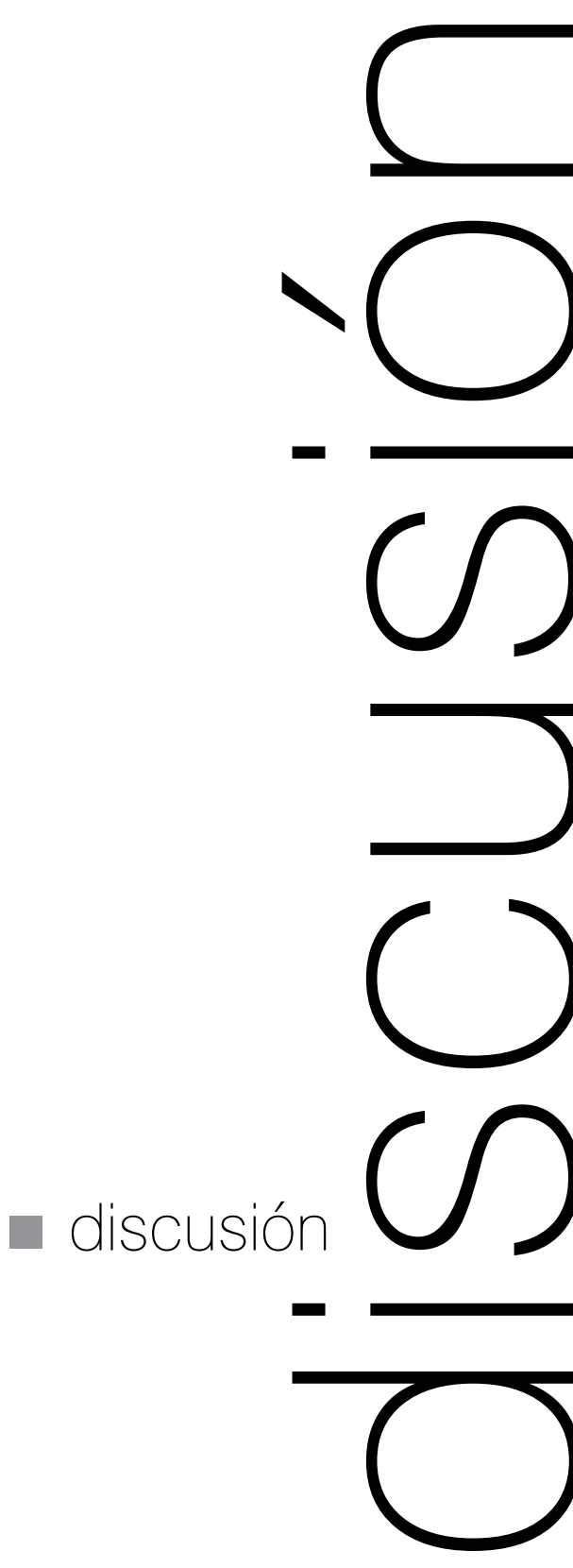


Rafael Filippelli

David Oubiña

Sergio Wolf

Hernán Hevia

Agustín Falco

Pedro Deré

Esta mesa de Discusión sobre La enseñanza del cine se realizó en el Encuentro de Cine Documental 2016, donde también se exhibió At Berkeley, de Frederick Wiseman. 


\section{La enseñanza del cine}

RAFAEL FILIPPELLI: Cuando empecé en el cine no había ningún lugar donde aprenderlo, salvo en la industria, haciéndolo. Esto no significó para mí ninguna frustración, y cuando las escuelas de cine aparecieron, en su apogeo, me sumé a ellas, pero ya como profesor. Debo reconocer que, casi viejo, haberme convertido en un profesor de cine, me cambió la vi$\mathrm{da}$, me convirtió en otra persona. Puedo afirmar que fue lo más importante que me pasó en mi vida cinematográfica. En primer lugar descubrí que los libros con los cuales iba a dar clase, los había leído hacía mucho tiempo, y no los había entendido. Además tuve que leer otros libros, nuevos, que me costaron mucho trabajo, y que me condujeron a pensar el cine nuevamente, en una edad madura. $Y$ de esa manera me convertí en una especie de coetáneo de una nueva generación de cineastas y pude ayudar, en la medida de mis posibilidades, al crecimiento de una nueva idea del cine. Esto me convirtió, luego, en amigo de aquellas personas, y hoy estoy orgulloso, y eso es gracias a la enseñanza del cine, de que muchos de ellos me acompañen en la Revista de cine. [El $\mathrm{N}^{\circ} 1$ de la Revista de cine apareció en 2014, su Director es Rafael Filippelli, su Secretario de Redacción es Sergio Wolf y el Comité de Dirección está integrado por R. Filippelli, Hernán Hevia, Mariano Llinás, Rodrigo Moreno, David Oubiña, Juan Villegas, S. Wolf.]

DAVID OUBIÑA: Con Sergio, Hernán, Nicolás Zukerfeld y Malena Solarz, dictamos «Historia del cine», en la Universidad del Cine. Antes, y durante muchos años, di clase de "Guión» con Rafael. También enseñé brevemente la materia «Guión documental», aunque todavía no sé en qué consiste esa materia. Recordábamos con Sergio la situación absurda cuando una vez 
se dio el premio de «Mejor actriz» al personaje de un documental y, en cierto sentido, creo que sucede lo mismo con el guión de un documental. Las dos materias que habité durante más tiempo (Historia del cine y Guión) son dos materias que, al menos en la Universidad del Cine, funcionan en dos líneas divergentes. «Historia del cine» es una de las materias «teóricas», junto a «Teoría» y «Crítica», mientras que «Guión», junto a «Dirección», «Montaje» o «Fotografía» son las materias «prácticas». Es cierto que nunca se sabe cuándo termina el día y cuándo empieza la noche, pero uno sabe cuándo es de día y cuándo es de noche. Aquí sucede lo mismo. Me parece que los límites entre esos territorios del cine son (y deberían ser) difusos. De todos modos, «Historia del cine» es una materia más tradicional, donde uno trata de instalar un conocimiento, y donde los estudiantes pueden elaborar ese conocimiento. La enseñanza es, en este caso, bastante clara. No digo que sea fácil, pero es algo claro: hay una serie de contenidos, una serie de conocimientos, que uno trata de impartir, y luego los estudiantes se aprovechan, o no, de esos conocimientos. En el caso de «Guión» tuve la impresión de que la materia tenía un tono más experimental y, por lo tanto, había algo del orden de lo imprevisto que funcionaba todo el tiempo en las clases. En un sentido era menos claro qué era lo que se enseñaba y cómo debía enseñarse. En el caso de «Guión», como en «Dirección», «Montaje» o «Fotografía», además de un conocimiento técnico (que por otra parte se agota muy rápidamente), uno trata de enseñar algo que, en rigor, se puede aprender pero no se puede enseñar. La clase no consiste tanto en fijar una serie de conocimientos, sino en construir un cauce por el cual pueda desarrollarse cierto impulso creativo.
Nunca creí en esa máxima acerca de que los profesores aprenden de los estudiantes. Yo no aprendo de mis estudiantes, nunca he aprendido «Historia del cine» de mis estudiantes. Quizá ellos tampoco aprendan nada de mí. Puedo aprender otras cosas de ellos, pero no «Historia del cine». En todo caso, sí aprendo cuando preparo las clases. Es en ese sentido que los estudiantes me permiten aprender: preparar las clases, pensando en esa serie de contenidos que deben ser transmitidos a los estudiantes, me ha enseñado a ser más claro en lo que comunico, tratando de sintetizar, de sugerir, de asociar.

Supongo que no se puede enseñar a escribir un guión. Arriesgándome, diría que quizá tampoco sea posible enseñar a dirigir una película, a montarla o a iluminarla. No se puede enseñar guión, aunque sí se puede aprender. Y lo que siempre he tratado de hacer es acompañar cierto aprendizaje.

Abbas Kiarostami dijo alguna vez que él se veía como una especie de director técnico de fútbol, como alguien que hacía todo el trabajo antes de que empezara el plano, porque cuando se larga el rodaje del plano, ya el director no tiene mucho que hacer.

Tiene razón. Nunca he entendido lo que hacen los directores técnicos durante el partido, pero lo cierto es que se han convertido en estrellas: a veces, la cámara muestra más al director técnico que a los jugadores que son los que están haciendo el trabajo en ese momento. El director técnico no trabaja durante el partido; ha trabajado en la semana, antes del partido. Yo trato de hacer eso en la clase de «Guión»: mostrar una serie de materiales, evaluar alternativas, promover una especie de gimnasia o de entrenamiento, no para resolver las cuestiones que se van a plantear en el rodaje, sino para tener una relación, un poco menos 
temerosa, con esos problemas, cuando se presenten. Si se han visto muchos ejemplos de cómo un director filma un travelling o cómo maneja los diálogos, quizá uno va a estar mejor preparado para enfrentar de qué manera se filma un travelling o de qué manera se formula un diálogo. Claro que tampoco hay ninguna garantía: ver muchos ejemplos de diálogos no necesariamente nos hará escribir un diálogo medianamente decoroso. Porque como el partido se juega en la cancha y, de la misma forma, en cada película todo debe comenzar de cero. Tal vez, entonces, lo que se puede enseñar es que nunca se debe adquirir un «oficio». Ésa es una palabra terrible en el dominio del cine. Como cuando se dice que tal director «tiene mucho oficio». Esto habla de alguien que enfrenta los problemas de una película de la misma manera que los encaró en una película anterior. Tener oficio significa dar respuestas viejas a problemas que siempre son nuevos. Lo más interesante del cine es justamente tener que enfrentar, en cada film, problemas nuevos. Cocteau decía que Picasso le había enseñado que hay que correr más rápido que la belleza, para que pareciera que uno le está dando la espalda. Uno trabaja todo la vida para construir un estilo y, cuando lo logra, queda preso de ese estilo. Los grandes cineastas son aquellos que todo el tiempo le escaparon al oficio y le escaparon a acomodarse en un estilo. Lo mejor que tiene el cine es que cada nueva película circula todo el tiempo al borde del naufragio. A veces, y solo a veces, la película logra salir a flote. Pero por eso tiene sentido hacer cine.

SERGIO WOLF: He sido docente durante muchos años, en cierto momento en la cátedra de «Guión documental», que ya ha sido mencionada por David. Pero pa- ra comenzar desearía hablar de mi experiencia como profesor de «Historia del cine». Hay cierto tabú respecto a la serie de temas de la Historia del cine y al tiempo que se le dedica a cada uno de esos temas, y en nuestro caso se transgredieron esos tabúes: se hicieron 4 clases sobre la Nouvelle vague, y una sola sobre Lumiére, Méliès, etc. Es decir la Historia del cine a partir de ejes problemáticos y no a partir de puntos del canon de esa historia del cine que se supone uno debe enseñar. $Y$ además pensando que frente al profesor se encuentran personas que van a hacer cine (realizadores o especialistas en alguno de los rubros "técnicos» del cine). No se trata entonces de enseñar ciertos textos o ciertos autores, sino pensar cuestiones que puedan incidir en las decisiones que esos cineastas o esos técnicos, van a tomar haciendo cine. La segunda cuestión tiene que ver con ese comunicar un saber, donde se debe plantear si lo que se hace es comunicar un hacer o se comparte una experiencia. Volvamos a la espinosa cuestión del Guión documental, y sigo sin saber qué es, y qué es lo que hay que enseñar. En ese recorrido, en el que me acompaña Nicolás Zukerfeld, hay 5 verbos que deben discutirse en esas clases: ver, discutir, leer, escribir y filmar. Creo que esos mismos verbos pueden ser utilizados en Historia del cine. Recuerdo que fugazmente di «Historia del cine argentino" y como trabajo práctico, en lugar de monografías que iban a repetir lo dicho en libros que ya había leído, los mandé filmar a personas que estaban vivas, y que podían contar parte de la historia del cine argentino. Les dije que no montaran ese material, que lo dejaran así, porque me bastaba con que hubieran hablado con esa gente. Fue el único año en que di esa materia, ya que me echaron, porque esa escuela de cine no tenía el equipamiento para 
que todos los alumnos hicieran ese trabajo práctico. Filmar debería ser una posibilidad para Historia del cine, dialogando con algunos actores de esa historia. Hay algún film de Spike Lee en respuesta a Griffith que podría ser un ejemplo.

La Maestría de cine documental en la FUC tiene pocos alumnos (es como un equipo que pelea todos los años el descenso, y alguna vez se va a ir al descenso), y el $90 \%$ de esos alumnos son extranjeros. Este dato, que supone una ventaja económica para la FUC, implica un problema: hay que trabajar el documental con extranjeros que acaban de llegar a Buenos Aires. Hacer un documental implica conocer los lugares, tener un contacto con la gente, poder entrar a las casas, y a un extranjero recién llegado eso se le hace difícil. Recuerdo que al comienzo todos los proyectos que presentaban eran documentales sobre la Feria de San Telmo. A tal punto que prohibimos pensar en filmar la Feria: fílmense en el baño, pero Feria de San Telmo, no. Hay que pensar, sin embargo, que esa predilección obedecía a una lógica: era la mirada del turista, que era lo que ellos eran en ese momento; una situación distinta se plantea en escuelas de cine que tienen mayoritariamente alumnos «locales». Me parece que lo más interesante de la enseñanza del documental es plantear la discusión de problemas que tienen que ver con la enseñanza y con el documental. Uno de esos problemas centrales, y que abordamos siempre en las reuniones de la Revista de cine, es el problema de la distancia. Es un problema general del cine, pero en el caso del documental, donde se plantean frecuentemente cuestiones «personales», el problema es cómo filmar a alguien «cercano», amigo, familiar. Es algo distinto al trabajo en la ficción y también distinto a cuando se filma a alguien ajeno a uno. Otro problema: qué pasa con la utilización de varias cámaras para filmar una situación. Recuerdo que un alumno que quería filmar a un predicador me dijo: «ya conseguí las 8 cámaras, la que va adelante, la que va atrás, etc.». Le dije que me había dicho que quería hacer una entrevista, y que para eso no necesitaba 8 cámaras. Contestó que quería tener todos los ángulos, pero esa película no se filmó y ya no tengo más a ese alumno. Otra cuestión tiene que ver con la posibilidad. A mí no me interesa cómo está escrito el proyecto de un documental, sino si puede o no realizarse, materializarse. Recuerdo el proyecto de un alumno, sobre un grupo de Médicos sin fronteras que estaba en una zona de Medio Oriente. El alumno era colombiano y ante la pregunta de cómo pensaba entrar en ese Medio Oriente, me contestó: no sé. Ese mismo alumno quería filmar en una ambulancia a personas en estado de emergencia, otra situación a la que no es posible acceder.

Otra cuestión es la posibilidad de formular distintas preguntas frente a cada uno de los proyectos, referidas a la discusión sobre la escritura y a la elección de los materiales. Cuando están determinados algunos proyectos, entonces elegimos films para ver y problemas para discutir que tengan vínculos con esos proyectos: personajes, lugares, textos en off, punto de vista, imágenes de archivo, etc. En la escritura del guión ya deben plantearse cuestiones que conciernen a los problemas del rodaje, a diferencia de las clases de «Guión», cuando se considera que los problemas de filmación vendrán «después». En el caso del trabajo en el documental, las cuestiones de rodaje deben ser pensadas desde la propia escritura. Finalmente debería plantearse, en el trabajo sobre el guión documental, la diferencia entre técnica y expresión. $\mathrm{O}$, si preferimos, entre producción y expresión. 
El proyecto no debe tener la lista de materiales o procedimientos, sino el sentido de su uso.

PEDRO DERÉ: Creo estar acá más como alumno que como profesor. En 1982 un grupo de jóvenes organizó un Festival de cine acá en Santa Fe, y en el 86, 87 me di cuenta de que quería hacer cine. Ahí encontré el Taller de Cine de la UNL. Desde hace 29 años estoy aprendiendo a hacer cine, enfrentando cada vez problemas nuevos. Alguien dijo que las técnicas del cine se aprenden en una noche. Aprendí con Raúl, con Marilyn, y después aprendí con Rafael. El Taller de Cine me dio el marco de referencia teórico, y la realización la aprendí trabajando con Rafael.

Tuve la suerte de comenzar filmando en $16 \mathrm{~mm}$. y entonces conocí Cinecolor, y trabajé en la Moviola, con el sonido a doble banda, y conocí Phonalex. Desempeñé en numerosos equipos de filmación, todos los rubros: producción, sonidista, montajista, realización, hasta hice cámara en algunos casos. Al cabo de los años, coincido con lo que ya se dijo: no sé si se puede enseñar, pero seguro se puede aprender.

AGUSTÍN FALCO: Desde hace 3 años enseño cine, y una experiencia que deseo compartir es lo que significó trabajar en una actividad de la Dirección de Educación Artística del gobierno de Santa Fe, en el diseño curricular de la llamada Educación Especializada en la Secundaria. Es un trayecto cercano al Doble turno, que no lo es pero se acerca, que tiene una considerable carga horaria de materias, digamos, artísticas, y que se aplica, acá en Santa Fe, en la Escuela Mantovani. $\mathrm{Si}$ es pertinente preguntarse si se puede enseñar cine a adultos que quieren ser cineastas, mucha más lo es, cuando se plantea enseñar cine a alumnos de la Secundaria. Hay algo que dificulta, o facilita la cuestión: hay muy pocas experiencias realizadas en las artes visuales que conciernen al cine.

Se encontró, por supuesto, fuerte resistencia de las áreas de las materias generales, de las materias duras y de las que no deberían ser tan duras. Además se trataba de preservar espacios, y entonces las materias de Historia del cine pasaron a llamarse «Artes audiovisuales y contexto", y los profesores de Historia trataron de adueñarse de ellas. También hubo conflictos de los espacios del cine de animación, con los de Diseño gráfico, y de los espacios del Documental con los Comunicadores sociales. Hubo conflictos de Puesta en escena con la gente de teatro, y de Guión con la gente de Letras, y Escenografía y arte con los arquitectos. Estos conflictos, y opciones, pueden ser considerados positivas, dado que se discuten estas cuestiones.

Participar en ese diseño curricular me convenció de lo necesario que son estos trayectos de enseñanza artística. Creo que son más necesarios esos espacios de enseñanza del cine para los estudiantes secundarios, que los espacios de enseñanza del cine para los futuros cineastas. En los espacios de enseñanza artística del secundario los alumnos se encuentran con contenidos que no sirven absolutamente para nada. Los otros espacios dan conocimientos útiles: historia, matemáticas sirven para algo.

En realidad la enseñanza artística sirve para saber que existen conocimientos que no son útiles en el sentido de la lógica capitalista.

No es fácil enseñar arte en el secundario. En primer lugar porque siempre se está en competencia con los otros conocimientos; nunca ocupa un lugar central, incluso en escuelas dedicadas al arte.

Por otra parte en cine el tiempo no es el mismo. Mien- 
tras en artes visuales los alumnos hacen cuarenta esculturas, en cine filman, montan y presentan una sola película.

La escuela, que es una serie de simulacros de aprendizajes actualmente, puede volver a tener un sentido, gracias al arte.

Tuve otra experiencia, cuando participé en el diseño de un Profesorado de Artes Audiovisuales. Todo Profesorado tiene 3 espacios: el de las materias generales, luego las materias específicas y después el de las prácticas de la enseñanza. El problema que puede plantearse es que estos profesores sean ajenos al hacer cinematográfico y solo formados en el plano pedagógico. Se perdería la vitalidad que da la experiencia artística.

Cuestiones interesantes se plantean respecto a la valoración que se da a prácticas experimentales, al cine documental y a las formas de expresión alternativas, como el Video arte. Porque al mismo tiempo que se intenta dar una formación clásica, se encaran las formas experimentales de las vanguardias.

Mis experiencias, en el Secundario y en la Enseñanza Superior, se desarrollan en la esfera de la escuela pública, en donde hay carencias tecnológicas muy grandes, y donde el alumnado es muy diverso, de orígenes sociales diferentes, donde hay estudiantes que pueden comprarse todo el equipamiento, mientras que otros tienen problemas para seguir estudiando.

Finalmente la técnica no puede ser limitante para la expresión, y en ese sentido debe tenerse cuidado con las expectativas que se alimentan desde el profesor, y plantearse qué quiere decir hacer cine o hacer arte. En general hay que bajar las expectativas de quienes comienzan a estudiar cine, o arte.

Uno ha visto muchas veces películas hechas por es- tudiantes de cine que presentaban manierismos deudores de la cultura televisiva, que imitaban modelos que no deberían ser imitados.

HERNÁN HEVIA: Habiendo pasado de un momento nítidamente de alumno a otro nítidamente de profesor, creo ver que, más allá del narcisismo de los individuos en el momento de crear, hay en toda enseñanza un trabajo a largo plazo. Se trata de comprender que una clase o una materia es un momento de una larga transición, nada más; y eso implica tender puentes entre profesor y estudiantes: uno puede enseñar cosas porque uno pudo aprenderlas.

Se puede estudiar hacer cine habiendo visto a Chaplin o a Buster Keaton. Puede alguien reírse sin prestarle atención a la puesta en escena. Por eso, si tomamos la enseñanza como una guía, creo que se puede enseñar: ¿cómo se construyó ese efecto que produjo risas?

Es difícil tender esos puentes con personas que no tienen esos saberes, para quienes todo es pura novedad. Sin embargo, el alumno más incómodo para un profesor es aquel que cree saber lo que dice el profesor, al mismo tiempo que lo está diciendo, como un eco. Lo que un alumno debe aprender es cuándo interrumpir, y cómo interrumpir, obviamente.

Esas interrupciones pueden ser provocadas, o facilitadas, por el profesor. A veces con provocaciones cualunquistas, como «no hay ningún film actual que valga la pena». Pero también hay provocaciones teniendo en cuanto el largo plazo, o «la tradición», cuando se dejan abiertas cuestiones temáticas o formales. Lo que se dice en una clase, a veces, después se convierte en un «rumor». Deseablemente no en un «eslogan», que es lo peor, sino en un rumor. $Y$ al transmitir 
ese rumor, esa bruma de saberes, puede que sea necesaria cierta precisión, otra precisión, que redunde en matizar, modificar, desmentir, etc., ese rumor, incluso si uno cree haberlo iniciado.

El primer momento de una clase es el de cierto perspectivismo. Ver cómo un problema puede ser abordado de un modo o de otro. Un profesor da una clase y otro profesor, sobre el mismo tema, da otra clase, totalmente distinta.

Y si tomamos el acto de componer una clase como una cuestión de puesta en escena, hay velocidades diferentes con las que explicar un tema u otro. ¿Cuándo mostrar un fragmento alusivo? ¿O ilustrar? Etc. Cuando se da Griffith, por ejemplo, y se comparan los dos asesinatos de Lincoln filmados por él, se ven problemas de puesta en escena en relación, en principio, a que el primero obedece a un marco narrativo más amplio (La Nación) y el segundo a una hagiografía, la del mismo Lincoln. El primero divide la película en dos; el segundo da pie al fin de la película. Al mismo tiempo, esos dos asesinatos no se exponen del mismo modo; casi que la proyección del segundo, si continúa la del primero, podría prescindir de comentarios de un profesor: Lincoln mismo da el discurso (para el pueblo, por el pueblo, ...) que en la primera versión no dio probablemente porque no se hubiera escuchado (más allá de que el Lincoln de carne y hueso no dijo ese discurso el día que lo asesinaron). No sólo por eso el segundo discurso genera risas.

Pero también el perspectivismo puede conducir a la parálisis. Preguntarse qué hacer ante la idea de filmar ese asesinato filmado tantas veces. Cómo puede introducirse una cuña, una pequeña inflexión dentro de esa tradición. Ahí creo que está la necesidad de enseñar a interrumpir.
Y ahí está el puente que se tiende y el alumno, en ese momento, o 5 días después, puede que diga: «Me quedé pensando, se me ocurrió esto». De esa manera se ampliaría la tradición.

Si tuviera que elegir un ejercicio para ayudar a tender ese puente elegiría el de ver un material a ciegas: un alumno muestra algo, que quizá no haya sido filmado por él, pero que lo ha tocado, pinchado, recordando a Roland Barthes, y debemos estudiarlo. Ese material podemos considerarlo a través de su densidad históri$\mathrm{ca}$, aún cuando ese material no sea consciente de esa densidad, tomando la morfología del encuadre, el uso de algunos lentes, el factor de corte, etc. Pero también podemos tomarlo con otro horizonte: el de la novedad. Entonces: para empezar, dos temporalidades. Quizá la noción de novedad sea algo ingenua: no se incorporan muchos saberes a través de los alumnos. Pero a veces a través del error, de lo que sale mal, se puede ver algo que se parece a una forma novedosa en estado germinal. Ese es el mejor momento del trabajo de enseñanza: no se sabe, nadie sabe, a priori qué hacer con algo.

Alguien interrumpió y uno está medianamente satisfecho con lo que generó esa interrupción. Dicen que en una clase de Deleuze en donde había un centenar de estudiantes, alguien se quedó dormido, y Deleuze pidió que no lo despertaran, pero que cuando se despertara, querría saber por qué se despertó.

Es cierto que ante un auditorio numeroso, ante una clase de 30 alumnos, es difícil mantener la atención, pero cuando se trabaja con pequeños grupos, y cuando aparece la técnica más dura, más resistente (como armar un carro de travelling), cuando aparece la técnica, no la tecnología, en esos casos se empieza a generar ese puente, incluso con chistes: «no demo- 
ren una hora y media en armar un travelling, porque va a parecer una película de Sokurov». Quien escucha ese chiste creo que puede percibir que hay un vínculo con ese saber denso, y también oscuro, que requiere estudio e incluso cierto grado de soledad, pero que conlleva un momento colectivo: si el carro no está nivelado quien empuja el carro va a tener otro problema, que va a ser diferente si está nivelado.

El largo recorrido de la enseñanza recuerda que una clase es una transición más, y que el ciclo se cierra, quizá 5 años después, cuando alguien te dice: «ahora me doy cuenta de aquello que decías», o "estabas equivocado en eso". Tender a esos momentos de la enseñanza, entre el perspectivismo y la técnica, es fundamental.

RAÚL BECEYRO: Creo que la enseñanza del cine, en su punto más incandescente, es enseñar a filmar, que es lo más difícil de enseñar. En la industria el momento del director, es la filmación. Antes están los guionistas, los productores, etc. y después está el montajista. El momento específico es la filmación. Uno se pregunta: ¿cómo se enseña a filmar?

En cierta ocasión Paola Rizzi dijo que nunca se termina de aprender a filmar; toda la vida se dedica a aprender a filmar. Nosotros utilizamos en las clases del Taller de Cine el Capítulo 35 del libro de memorias de John Huston llamado «A libro abierto». En ese libro, donde Huston cuenta su vida aventurera, hay un capítulo, hacia el final, donde Huston da una especie de lección de cine, y sobre todo, una lección de cómo filmar. [El Capítulo 35 de Huston puede leerse online en el $\mathrm{N}^{\circ} 10$ de los Cuadernos de Cine Documental, en la Biblioteca Virtual de la UNL/Publicaciones periódicas/Cuadernos de cine documental.]
En ese texto Huston da indicaciones precisas sobre cómo filmar, pero lo curioso es que habla como si el guión no existiera, o como si habiendo existido, deba ser corroborado en el lugar de la filmación, en el momento de la filmación. Huston fue guionista, y sabe mucho de todo eso, pero me parece que se trata de una estrategia destinada a enfrentar el monstruo de la filmación.

Porque si se tiene en la mano el guión, o, peor, el guión «técnico», entonces todo es fácil: Toma 1: PG Cocina, TRAV. LAT. hasta DET de jarra de leche, etc. Todo eso es fácil, pero es falso. Huston dice que se llega y se comienza a filmar cronológicamente, es decir desde el comienzo. Se ensaya la situación (o, en un documental, se ve, o se prevé, la situación) y entonces se toma la primera decisión: "Cámara acá». Es decir que desde ese lugar se va a ver el comienzo de la situación. Luego se ve la altura de la cámara, y el plano elegido, que depende de la distancia real y del objetivo, tratando de enseñar algo que es imposible de enseñar. Ese es el núcleo incandescente de la enseñanza del cine.

En uno de los Encuentros de Cine documental, organizados por el Taller de Cine, se habló de un cineasta que «sabía filmar». Es un poco lo del «oficio» del que ya se habló. ¿Qué quiere decir saber filmar? El saber filmar constituye algo que hay que enfrentar de una buena vez.

Creo que se ha hablado varias veces del guión documental, de manera despectiva. Tomemos en primer lugar el guión, que es un objeto que tiene dos funciones: en primer lugar puede ser leído por alguien para que tenga una idea de cómo puede ser esa futura película. Pero por otro lado el guión es el instrumento utilizado por el cineasta para filmar. $Y$ puedo 
asegurar, y quienes han hecho documentales pueden corroborarlo, que siempre, en todos los casos, se ha comenzado la filmación teniendo en la mano un guión. Y eso se llama guión documental. Así que creo que debe existir la Materia Guión documental I, y también Guión documental II, etc., para que ese papelito con el que uno enfrenta la filmación tenga el mayor grado de consistencia posible.

Recuerdo que en una ocasión vino Mario Bomheker, vimos su film Cuentas del alma, y ahí figuraban como "guionistas", junto a Bomheker, Carmen Guarini y Susana Romano Sued. Hablando se vio que en realidad ambas habían trabajado con el material ya filmado, y entonces uno se preguntaba por qué no habían sido llamadas «montajistas», ya que su trabajo se había realizado después de la filmación, mientras que el trabajo de los guionistas se realiza antes de la filmación.

H. HEVIA: Se planteó la cuestión de cómo se enseña el acto específico de filmar. Diría que generalmente «de costadito». Cuando estamos frente a alguien que está filmando, uno solo puede hacer un gesto, o mandar a alguien, un amigo del director, para que le diga alguna cosita. Se trata de no usurpar su lugar, y no hacer decaer la tensión de toda filmación.

Al mismo tiempo, son necesarios algunos actos reflejos: una técnica mínima, si se quiere. Cuando en una clase hay que armar un carro hay que enseñar dónde poner el pelícano para que no le saque tres centímetros a una eventual panorámica. Otro caso: un caña necesita que el ángulo del micrófono esté mejor direccionado para grabar directo pero posicionarse para eso produce su sombra, que obviamente depende de un farol. El montajista, si estuviera en rodaje, podría indicar tres momentos de corte en una toma. Y así con todo lo involucrado en una película. Ante la tensión del rodaje (también hay tensión al momento de discutir una línea de diálogo con los actores o la entrada de un sonido, pero, en estos casos, suele haber más tiempo) una técnica de base concentra: ayuda a ordenar prioridades y a que, ante la simultaneidad de variables, la composición de ese plano no redunde inexorablemente en reproducir uno ya visto, que, además, en lo posible, tiene que ser una referencia para todos los que están trabajando en ese rodaje, sino, de otra manera, habrá que describirlo un sinnúmero de veces y ese tiempo que se calculó para la filmación de un plano redundará en su explicación (gesto contemporáneo que se extiende incluso mucho después del estreno de las películas). Simplemente, una técnica invisible gana tiempo para ir viendo y escuchando «sobre la marcha»; y así quizás ese plano citado no se simplifique cada vez que se vuelve a él.

MARILYN CONTARDI: Se trata siempre de ver qué se mira. Si se hace, por ejemplo, una panorámica, si esa panorámica no reemplaza una mirada, no sirve para nada. Vemos innumerables panorámicas que no sirven para nada. Incluso panorámicas «bien hechas»: regulares, sin salto. Pero eso no alcanza; siempre la cuestión es qué se mira.

Recuerdo cuando filmamos la inundación del 2003, el día después, con la basura y los elementos destruidos por el agua. Eso tenía que ser visto como por un vecino que andaba husmeando, si no no servía. Antes de poder filmar se debe materializar esa mirada.

R. BECEYRO: Para poder disfrutar de la mirada de un gran cineasta ahora veremos At Berkeley, de Frederick Wiseman. 